\title{
招請講演 I
}

\section{Thoracic Surgery Education and Certification}

\author{
John R. Benfield, M. D. \\ (University of California at Davis School of Medicine)
}

How has thoracic surgery education in the United States (US) evolved? What are the strengths of the US system? How might improvements be made? What are the challenges now faced by US thoracic surgical educators?

Thoracic surgery residency education became formal and separately identified first at the University of Michigan. Other leading institutions, including mine at the University of Chicago, preferred to teach thoracic surgery as integrated part of surgical education. In 1948, The Board of Thoracic Surgery was created as an affiliate of the American Board of Surgery (ABS). About 2 decades later the American Board of Thoracic Surgery (ABTS) became independent of ABS. Directors of ABTS serve 6 year terms during which they examine and certify graduates of approved residencies. An independent Residency Review Committee (RRC) in thoracic surgery stipulates the requirements for approved programs which are then regularly evaluated by the RRC. The curriculum for approved residencies is the product of the Thoracic Surgery Directors Association (TSDA). Thus, TSDA guides how and what to teach, RRC is responsible for independent assessment of the programs, and ABTS certifies individuals who have graduated from thoracic surgery residencies.

The strengths of the US system have included insistence upon accepting for thoracic surgery education only young men and women who are already independent, certified general surgeons with about 6 years of experience and fundamental education. The RRC approval process assures that thoracic surgery training programs all meet requirements that include 2-3 years in a well supervised, progressively independent practice in thoracic surgery. ABTS certification serves as a well accepted standard of evaluation.

Improvements that might be made were the subject of a September 1996 TSDA Retreat. It was agreed that thoracic surgery educators should become actively involved in the education of thoracic surgeons as soon as possible after medical school graduation. By doing so, thoracic surgical educators could bring about even better thoracic surgery education than in the past. TSDA said that the thoracic surgery subspecialities of cardiovascular surgery for adults, general thoracic surgery and congenital heart surgery should remain together.

The challenges in thoracic surgery education come from the following: 1) The ever 
growing knowledge and complexity of technology in thoracic surgery ;2) The economic pressures that are demanding more efficient health care without full appreciation of the importance of quality ; 3) The erroneous belief that speciality medical care is less expensive than care given by generalists. Thoracic surgery in the 20 th Century has shown what remarkable progress can be made by well educated men and women. Thus as the 21st Century approaches, one can be sure that thoracic surgery education will become better while nonetheless staying within the bounds of society's resources.

Knowledge, research and excellence in education know no national boundaries. US thoracic surgery has benefited enormously from international interchange. I was honored 40 years ago when Professor Urabe of Kanazawa allowed me to present in Japan the findings of my first research project. Fifteen years later, I had the privilege of serving as the host for some of Professor Katsuki's residents from Chiba who joied me for periods of 1-3 years in California. Now I am delighted and honored to return to Kanazawa upon the invitation of Professor Watanabe and the Japanese Association for Chest Surgery. 